This item was submitted to Loughborough's Research Repository by the author.

Items in Figshare are protected by copyright, with all rights reserved, unless otherwise indicated.

\title{
Design and characterization of a three material anatomical bone phantom for implanted antenna applications
}

PLEASE CITE THE PUBLISHED VERSION

https://doi.org/10.1049/cp.2017.0253

\section{PUBLISHER}

(C) Institution of Engineering and Technology (IET)

\section{VERSION}

AM (Accepted Manuscript)

\section{PUBLISHER STATEMENT}

This work is made available according to the conditions of the Creative Commons Attribution-NonCommercialNoDerivatives 4.0 International (CC BY-NC-ND 4.0) licence. Full details of this licence are available at: https://creativecommons.org/licenses/by-nc-nd/4.0/

\section{LICENCE}

CC BY-NC-ND 4.0

\section{REPOSITORY RECORD}

Symeonidis, Symeon, W.G. Whittow, and C.J. Panagamuwa. 2019. "Design and Characterization of a Three Material Anatomical Bone Phantom for Implanted Antenna Applications". figshare. https://hdl.handle.net/2134/34922. 


\title{
Design and characterization of a three material anatomical bone phantom for implanted antenna applications
}

\author{
Symeon Symeonidis, William G. Whittow and Chinthana Panagamuwa \\ Wolfson School of Mechanical, Electrical and Manufacturing Engineering, Loughborough University, Loughborough, \\ Leicestershire, $U K$ \\ S.Symeonidis@lboro.ac.uk,w.g.whittow@lboro.ac.uk,c.j.panagamuwa@lboro.ac.uk
}

Keywords: Multilayer anatomical phantoms, implanted antennas, biomedical applications, wireless communications

\begin{abstract}
This work presents the development and testing of a three layer anatomical human body phantom suitable for microwave applications. The proposed phantom consisted of bone marrow, bone cortical and muscle layers. The ingredients used for each tissue along with the calculation of the mean square error of the dielectric properties showed good agreement with the dielectric properties of real life tissues and the IEEE SAR measurement standard for tissue mimicking phantoms. The geometrical characteristics of the bone layer can be adjusted to fit the geometry of any desired bone in the human body. The suitability of the phantom has been tested using an implanted antennas application, which has yielded comparable simulation and measurement results.
\end{abstract}

\section{Introduction}

In the RF communication field, human body phantoms are regularly used for simulations and measurements in applications such as implanted antennas, implanted sensors and SAR measurements [1]-[5]. The most common geometries for designing human body phantoms are cubic [6], cylindrical [1] and spherical [7]. These geometric types are frequently used to simulate parts of the human body in order to validate the electromagnetic interaction of the human body and the antenna.

The selection of dimensions for a body phantom is an important issue as the efficiency of the radiator is highly dependent on the position inside the body. As the depth of the implant increases, the number of tissues that surround it increases and the total permittivity and conductivity of the investigated area may vary. To avoid the approximations of phantoms, lamb, pork or rabbit joints are often used [5][27]. This can provide a realistic heterogeneous geometry when measuring implanted devices but due to the process that commercially available meat undergoes (maturation in low humidity and blood draining), the dielectric properties of the investigated part may vary in some cases and lead to mismatches between simulations and measurements [8]. Additionally, an animal joint is generally quite costly and difficult to handle hygienically in a communications lab environment, and is unsuitable for lengthy measurement campaigns.

Multilayered phantoms, such as the phantom presented in this paper, are used when the performance of an implanted radiator with respect to the surrounding tissues is investigated [9]. These types of phantoms usually consist of bone, fat, and muscle layers, their development requires the combination of multiple recipes and can offer a detailed representation of the investigated body part in terms of geometry and electromagnetic characteristics [1]-[5]. Each layer has a specific recipe and thickness according to its equivalent tissue. The recipes are either gels for high permittivity and conductivity materials or flour based for lower values of permittivity or conductivity. Combining multiple tissue layers can often result to undesirable mixing of ingredients among their contact area. This can adversely affect the properties of the phantom. Therefore it is important to use high amounts of gelatine for high permittivity and conductivity recipes. Gelatine can increase the solidity of the particular layers reducing the mixing effect to a minimum[10]-[12].

The remainder of this paper presents the development and testing the anatomical three layer phantom consisting of bone marrow, bone cortical and muscle. The bone marrow and bone cortical are cylinders and their geometry represent real life values taken from a femur bone found in [13]. The technique can be applied to any other bone in the body. The suitability of the phantom is investigated using a two-monopole implanted test bed.

\section{Simulation of a three layer anatomical phantom}

The CST Microwave Studio EM software was used for the simulations presented below. The permittivity and conductivity of the simulated phantom layers were frequency dependent and their values mimicked Gabriel's measurements [14] at the frequency range of 0.5 to $4 \mathrm{GHz}$. The dimensions of the muscle layer were $8.5 \times 17 \times 23 \mathrm{~cm}(\mathrm{H} \times \mathrm{W} \times \mathrm{L})$. The bone cortical and bone marrow cylinders were $12 \mathrm{~cm}$ long and had diameters of $4 \mathrm{~cm}$ and $2 \mathrm{~cm}$ respectively. An antenna test bed consisting of two monopoles was created for the investigation of the electromagnetic wave propagation inside the phantom. It is envisioned that the proposed test bed will re-enact the metal pins of an external medical metal plate for bone fracture monitoring applications, as presented in our previous work 
[15]. The conducting parts of the monopoles were implanted into the bone and muscle layers of the simulated three layer phantom. The length of each monopole was $4 \mathrm{~cm}$ and was connected with the groundplane that was in free space at the bottom of the phantom. The dimensions of the groundplanes were chosen to be $8 \times 9.5 \mathrm{~cm}$ (see Figure 1a) in order to achieve good support of the monopoles perpendicularly along the bone axis in measurements presented in Section 4. The groundplanes were attached to the parts of the monopoles that were exposed on the surface of the phantom (see Figure 1b). A gap of $4 \mathrm{~mm}$ between the groundplanes was selected in order to ensure separation between them. The monopoles and groundplanes were coated with biocompatible PLA insulator and the distance between them was $2 \mathrm{~cm}$ as it was found in previous research to be a good trade-off between distance and wave attenuation [15] inside the phantom. Achieving a $2 \mathrm{~cm}$ distance between the conductors required the monopoles to be placed $0.8 \mathrm{~cm}$ off the edge of the ground plane in the x-axis. The $S_{11}$ and $S_{21}$ of the monopoles was simulated and compared with the measured results in Section 5.

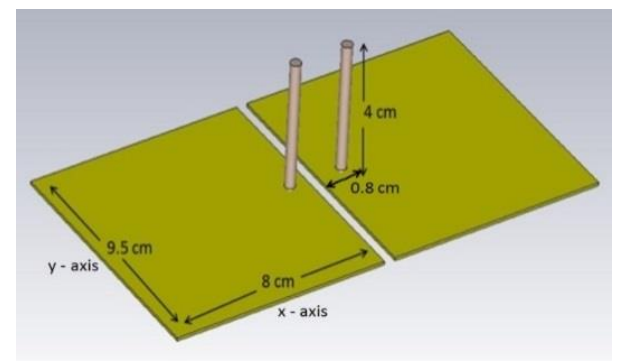

a)

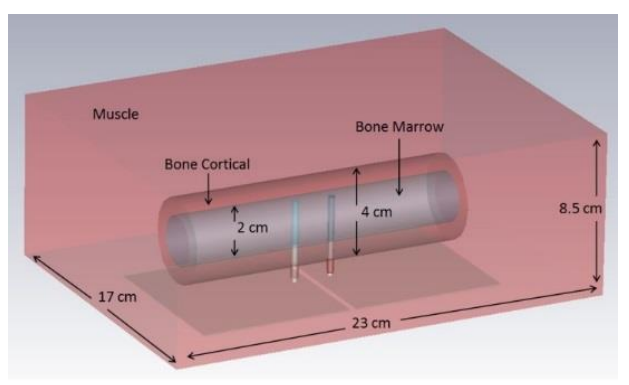

(b)

Figure 1: a) The two monopole test bed; b) the monopoles in the simulated three layer phantom

\section{Development of the three material anatomical tissue mimicking phantom}

Using the known results from literature along with the conducted experimental analysis, the recipes for bone marrow, bone cortical and muscle phantom layers were developed. Bone marrow and bone cortical were designed to be solid, while muscle had a semi-solid form.

\subsection{Phantom Materials}

Deionized water has a relative permittivity of 77.63 and a conductivity of $0.25 \mathrm{~S} / \mathrm{m}$ at $1 \mathrm{GHz}$. By adding sugar the relative permittivity of the mixture reduces. Adding salt $(\mathrm{NaCl})$ increases its relative permittivity and conductivity; adding oil, either vegetable or olive, will decrease both these parameters over the desired frequency spectrum. It is important to mention that oil will not mix in water because water molecules form a polar covalent bond and oil molecules have non-covalent bonds. In order to mix oil and water, a detergent containing surfactants is required for the reduction of the tension between molecules [16]. The detergent used for these measurements contained $15-30 \%$ anionic surfactants and $5-15 \%$ nonanionic surfactants. Gelatine was used as a solidifying agent for the mixture. A similar approach for developing phantom recipes can be found in [11].

\subsection{Characterising the phantom layers}

For the measurements of the dielectric parameters of each recipe, an open ended RG-402 semi-rigid coaxial cable - probe connected to an Anritsu MS46524A vector network analyzer that was calibrated over the 0.5 to $4 \mathrm{GHz}$ frequency range was used. Detailed analysis on the operation principles of open ended probes for relative permittivity measurements of liquids can be found in [17].

An amount of $300 \mathrm{ml}$ of each measured material was put into a $350 \mathrm{ml}$ cylindrical plastic cup of $3.5 \mathrm{~cm}$ radius. Each measurement was taken by immersing the coaxial probe into the middle of the cup at $3 \mathrm{~cm}$ depth, thus good contact between the probe and the sample was achieved. With the probe in place, its reflection coefficient was measured on the VNA and the dielectric properties of the each mixture were calculated using the functions found in [18].

\subsection{Phantom construction}

Each of the recipes of the phantom layers were devised through trial and error by mixing the constituent materials in varying ratios. Once perfected, the same recipe was followed twice more to verify the process was repeatable and the results consistent. At each attempt, the permittivity and conductivity properties were measured three times and an average was taken. A similar approach can be found in [11]. Table 1 shows the amount of ingredients required for each recipe.

\section{Bone marrow and bone cortical:}

1) Flour and olive oil were mixed for 10 to 15 minutes until all of the oil was completely absorbed by the flour;

2) The necessary amount of deionized water was added and the mixture was kneaded until all of the water was absorbed.

\section{Muscle:}

1) $200 \mathrm{ml}$ of deionized water was heated to $55^{\circ} \mathrm{C}$;

2) $5 \mathrm{~g}$ of gelatine was mixed and stirred slowly until the temperature of the liquid reduced to $30^{\circ} \mathrm{C}$;

3) Olive oil and the detergent were added and the mixture was stirred until they were homogenised; 
4) The mixture was put in a refrigerator to solidify overnight;

5) Once set, the mixture was removed from the refrigerator and left to return to room temperature.

A ten minute resting period was given after the final step for each recipe was completed. Since each mixture was produced three times, and each time the dielectric properties measured three times, nine measurements in total were taken for each recipe. The final average consisting of the averages of each set of measurements was calculated. Table 2 describes the meansquare error (MSE) for $\varepsilon_{r}$ and $\sigma$ of the measured data compared to the Gabriel et al. for the equivalent real life body tissues. The resulting error for the desired frequency spectrum is smaller by at least $10 \%$ compared to previously reported broadband phantoms at the same frequencies [25]-[27].

Table 1: Tissue-mimicking recipes for 0.5 to $4 \mathrm{GHz}$

\begin{tabular}{lccc}
\hline Ingredient $(\mathrm{g})$ & $\begin{array}{c}\text { Bone } \\
\text { Marrow }\end{array}$ & $\begin{array}{c}\text { Bone } \\
\text { Cortical }\end{array}$ & Muscle \\
\hline Flour & 80 & 80 & - \\
Oil & 33 & 30 & 31 \\
Deionized water & 3 & 10.5 & 200 \\
Food colouring & 1 & - & - \\
Sugar & - & 7.2 & - \\
Detergent & - & - & 31 \\
\hline
\end{tabular}

Table 2: The mean square error of the tissue-mimicking recipes vs tissue dielectric values for 0.5 to $4 \mathrm{GHz}$

\begin{tabular}{lccc}
\hline Mean Square error & $\begin{array}{c}\text { Bone } \\
\text { Marrow }\end{array}$ & $\begin{array}{c}\text { Bone } \\
\text { Cortical }\end{array}$ & Muscle \\
\hline $\begin{array}{l}\text { Relative } \\
\text { Permittivity }\end{array}$ & 0.0316 & 0.141 & 1.146 \\
Conductivity (S/m) & 0.001 & 0.016 & 0.06 \\
\hline
\end{tabular}

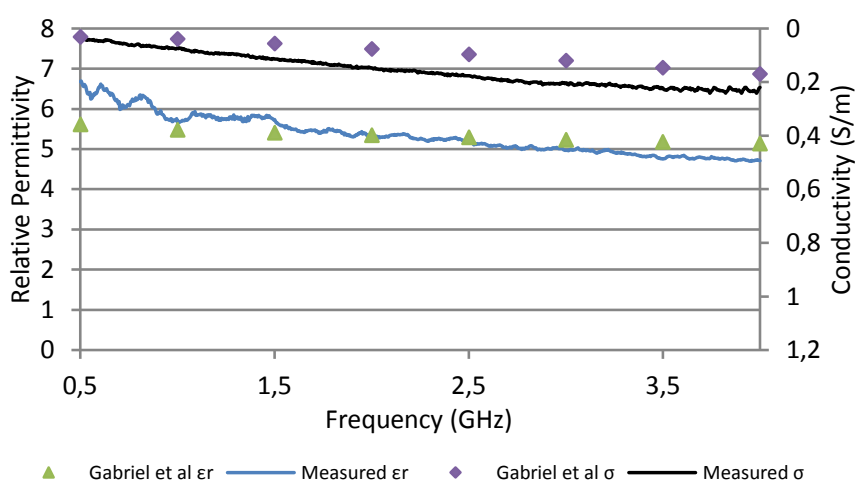

Figure 2: Bone marrow dielectric parameters

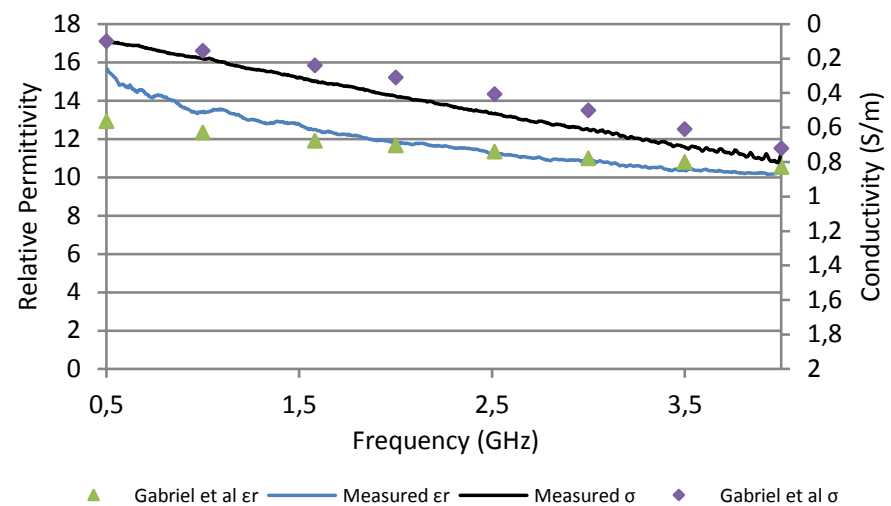

Figure 3: Bone cortical dielectric properties

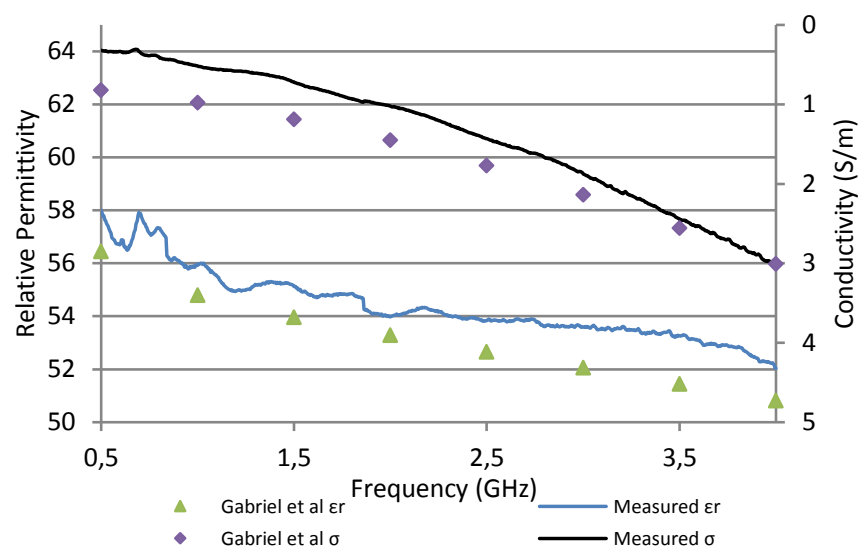

Figure 4: Muscle layer dielectric properties

The dielectric properties of the presented phantom comply with the IEEE SAR measurement standard for tissue- mimicking phantoms recipes. According to SAR, the measured conductivity and relative permittivity between $300-2000$ $\mathrm{MHz}$ should be within $\pm 5 \%$ and for $2-3 \mathrm{GHz}$ measured conductivity should be within $\pm 5 \%$ and relative permittivity within $\pm 10 \%$ from the target values [19].

The bone consisted of two layers, bone marrow and bone cortical. The bone cortical layer was flattened to a thickness of $1 \mathrm{~cm}$ and wrapped around the bone marrow layer (see Figure 5 ). The diameter of the final bone was $4 \mathrm{~cm}$ and had a length of $12 \mathrm{~cm}$. The dimensions of the muscle layer were $17 \times 23 \mathrm{~cm}$ and $8.5 \mathrm{~cm}$ high. A rectangular area on top centre of the muscle layer with dimensions of $4 \times 4 \times 12(\mathrm{H} \times \mathrm{W} \times \mathrm{L})$ was removed in order to create space for the placement of the bone layer. After the bone layer was in position, the remaining air gaps in the area were carefully filled with parts of the previously removed muscle layer.

\section{Antenna measurement setup and results}

The two monopoles described were inserted through the top of the muscle into the bone layer (see Figure 6). The distance between them was $2 \mathrm{~cm}$ and the length of each one was $4 \mathrm{~cm}$, the thickness of the groundplanes was $2 \mathrm{~mm}$ and they were 
separated by a $4 \mathrm{~mm}$ distance. A $0.5 \mathrm{~mm}$ layer of plastic tape was wrapped around the monopoles and also stuck to the grounplanes in order to avoid short circuiting with the highly conductive muscle layer.

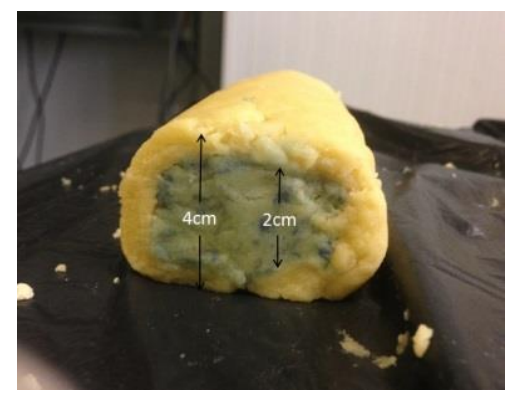

Figure 5: Bone cortical wrapped around bone marrow

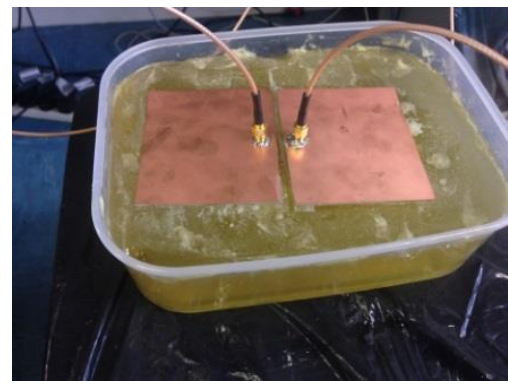

Figure 6: Monopoles implanted into the three layer phantom

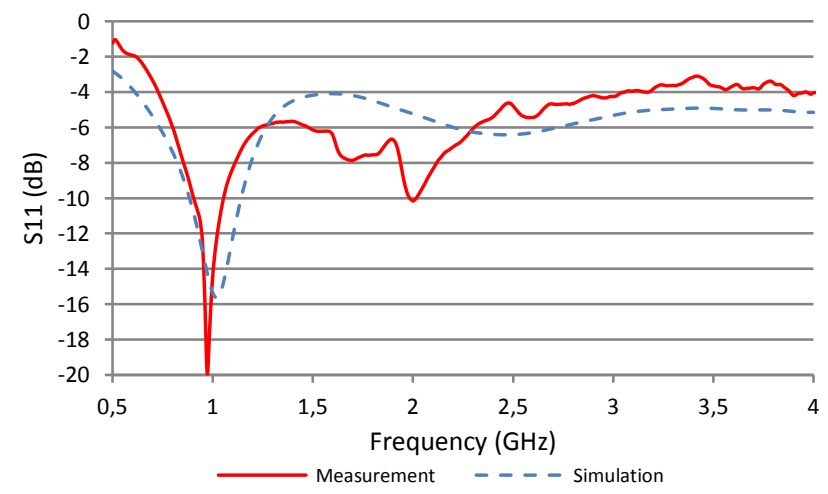

Figure 7: Simulated and measured $S_{11}$

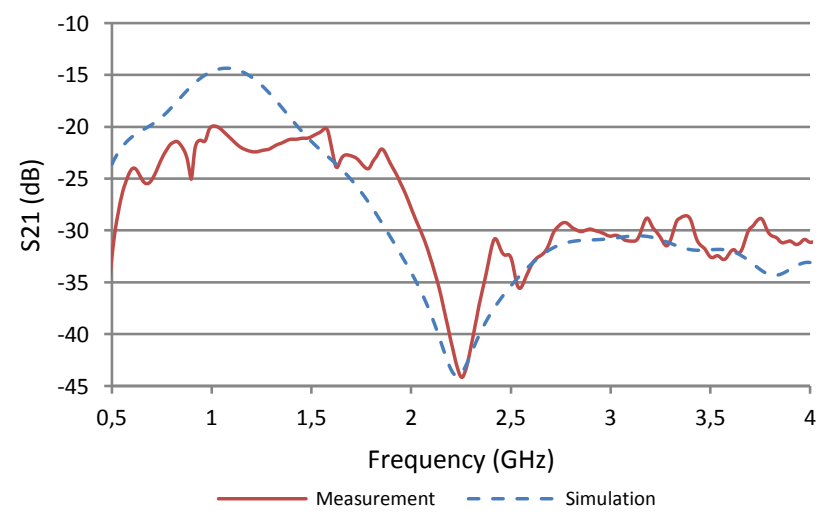

Figure 8: Simulated and measured $S_{21}$
Figure 7 and figure 8 show that there is good agreement in the $S_{11}$ and $S_{21}$ between the simulated and the measured phantom. This is due to the minimum mean square error between the values of dielectric properties of the recipes and the measured dielectric properties of Gabriel (see Table 2). Additionally, the precise replication of the simulated geometry into the measured test-bed offered a good match between the simulated and the measured power transfer of the two monopoles. Some small deviation of the measured scattering parameters is expected due to the unwanted mixing of the ingredients in the contact area among the layers of the phantom. The energy of the propagated wave in these areas can lead to the formation of standing waves that can cause minor frequency discrepancies.

\section{Conclusion}

The presented relative permittivity and conductivity of the phantom layers showed good agreement with those presented by Gabriel et al[14] in the frequency range 0.5 to $4 \mathrm{GHz}$. The mean square error was better than required in the IEEE SAR measurement standard. Tests with implanted monopoles showed that simulation results can be recreated in measurements. Therefore, the presented three material anatomical phantom could provide a low cost, repeatable, easy to handle, and hygienic alternative for electromagnetic in-vitro measurements. Furthermore, the flexibility in the design and construction means that the phantom can be adjusted to match the geometry of many bones of the human body.

\section{References}

[1] T. Dissanayake, K. P. Esselle, and M. R. Yuce, "Dielectric loaded impedance matching for wideband implanted antennas," IEEE Transactions on Microwave Theory and Techniques, vol. 57, no. 10, pp. 2480-2487, 2009.

[2] E. Y. Chow, C.-L. Yang, A. Chlebowski, W. J. Chappell, and P. P. Irazoqui, "Miniature antenna for RF telemetry through ocular tissue," 2008 IEEE MTT$S$ International Microwave Symposium Digest, pp. 1309-1312, 2008.

[3] M. Khan, S. P. S. M. A. Sirdeshmukh, and K. Javed, "Evaluation of bone fracture in animal model using bio-electrical impedance analysis," Perspectives in Science, pp. 4-6, 2016.

[4] T. Yoshida, W.-C. Kim, K. Kawamoto, T. Hirashima, Y. Oka, and T. Kubo, "Measurement of bone electrical impedance in fracture healing.," Journal of orthopaedic science, vol. 14, no. 3, pp. 320-329, 2009. T. Yoshida, W.-C. Kim, Y. Oka, N. Yamada, and T. Kubo, "Assessment of distraction callus in rabbits by monitoring of the electrical impedance of bone.," Acta orthopaedica, vol. 81, no. 5, pp. 628-633, 2010.

[6] W. Xia, K. Saito, M. Takahashi, and K. Ito, "Performances of an implanted cavity slot antenna embedded in the human arm," IEEE Transactions on Antennas and Propagation, vol. 57, no. 4, pp. 894899, 2009.

[7] J. Kim and Y. Rahmat-Samii, "Implanted antennas 
inside a human body: Simulations, designs, and characterizations," IEEE Transactions on Microwave Theory and Techniques, vol. 52, no. 8, pp. 1934-1943, 2004.

[8] J. L. Damez, S. Clerjon, S. Abouelkaram, and J. Lepetit, "Beef meat electrical impedance spectroscopy and anisotropy sensing for non-invasive early assessment of meat ageing," Journal of Food Engineering, vol. 85, no. 1, pp. 116-122, 2008.

[9] T. Karacolak, A. Z. Hood, and E. Topsakal, "Design of a dual-band implantable antenna and development of skin mimicking gels for continuous glucose monitoring," IEEE Transactions on Microwave Theory and Techniques, vol. 56, no. 4, pp. 1001-1008, 2008.

[10] R. King, S. Prasad, and B. Sandler, "Transponder antennas in and near a three-layered body," Microwave Theory and Techniques, vol. 28, no. 6, pp. 586-596, 1980.

[11] A. Sani, M. Rajab, R. Foster, and Y. Hao, “Antennas and propagation of implanted RFIDs for pervasive healthcare applications," Proceedings of the IEEE, vol. 98, no. 9, pp. 1648-1655, 2010.

[12] T. Yilmaz, S. Member, R. Foster, and Y. Hao, "Broadband Tissue Mimicking Phantoms and a Patch Resonator for Evaluating Noninvasive Monitoring of Blood Glucose Levels," IEEE Transactions on Antennas and Propagation, vol. 62, no. 6, pp. 30643075, 2014.

[13] R. Augustine, S. Raman, and A. Rydberg, "Microwave Phantoms For Craniotomy Follow-Up Probe Development," in 2014 IEEE Conference on Antenna Measurements \& Applications (CAMA), 2014.

[14] L. M. Marshall, T. F. Lang, L. C. Lambert, J. M. Zmuda, K. E. Ensrud, and E. S. Orwoll, "Dimensions and volumetric BMD of the proximal femur and their relation to age among older U.S. men.," Journal of bone and mineral research: the official journal of the American Society for Bone and Mineral Research, vol. 21, no. 8, pp. 1197-206, 2006.

[15] S. Symeonidis, C. Torres-Sanchez, C. Panagamuwa, and W. G. Whittow, "An Implanted Antenna System for the Monitoring of Bioresorbability of a Biocompatible Scaffold Embedded into a Bone Fracture," in Mobihealth, 2015, pp. 1-4.

[16] S. Symeonidis, W. G. Whittow, C. J. Panagamuwa, and M. Zecca, "An Implanted Antenna System for the Monitoring of the Healing of Bone Fractures," in 2015 Loughborough Antennas \& Propagation Conference (LAPC), 2015, pp. 1-4.

[17] S. Symeonidis, W. . Whittow, and C. J. Panagamuwa, "Characterisation of an Antenna System Implanted Into a Limb Phantom for Monitoring of Bone Fracture Healing," Loughborough Antennas \& Propagation Conference (LAPC), 2016.

[18] C. Gabriel, "Compilation of the Dielectric Properties of Body Tissues at RF and Microwave Frequencies," Environmental Health, p. 21, 1996.

[19] J. L. Salager, A. M. Forgiarini, and J. Bullón, "How to attain ultralow interfacial tension and three-phase behavior with surfactant formulation for enhanced oil recovery: A review. Part 1. Optimum formulation for simple surfactant-oil-water ternary systems," Journal of Surfactants and Detergents, vol. 16, no. 4, pp. 449472, 2013.

[20] T. P. Marsland and S. Evans, "Dielectric measurements with an open-ended coaxial probe," IEEE Proceedings in Microwaves, Antennas and Propagation, vol. 134, no. 4, p. 341, 1987.

[21] C. J. Panagamuwa, I. Howells, and W. G. Whittow, "Conductivity and permittivity measurements of children and adult's hands covering mobile communications frequency bands," Progress In Electromagnetics Research Symposium (PIERS), pp. $1-5,2013$.

[22] B. García-Baños, J. M. Catalá-Civera, A. J. Canós, and F. Peñaranda-Foix, "Design rules for the optimization of the sensitivity of open-ended coaxial microwave sensors for monitoring changes in dielectric materials," Measurement Science and Technology, vol. 16, no. 5, pp. 1186-1192, 2005.

[23] D. M. Hagl, D. Popovic, S. C. Hagness, J. H. Booske, and M. Okoniewski, "Sensing volume of open-ended coaxial probes for dielectric characterization of breast tissue at microwave frequencies," IEEE Transactions on Microwave Theory and Techniques, vol. 51, no. 4 I, pp. 1194-1206, 2003.

[24] R. B. Keam and J. R. Holdem, "Permittivity measurements using a coaxial-line conical-tip probe," Electronics Letters, vol. 33, no. 5, p. 353, 1997.

[25] M. H. Moussa, M. A. Abu-Khousa, and N. N. Qaddoumi, "Measurement of liquids dielectric property using monopole probes operating at microwave frequencies," Proceedings of the IEEE International Conference on Electronics, Circuits, and Systems, vol. 3, pp. 1204-1207, 2003.

[26] N. N. Suwan, M. S. Boybay, and O. M. Ramahi, "ENG-sensor: Enhanced open-ended coaxial line sensor for material characterization application," 2010 IEEE International Symposium on Antennas and Propagation and CNC-USNC/URSI Radio Science Meeting - Leading the Wave, AP-S/URSI 2010, pp. 36, 2010.

[27] Z. W. Z. Wang and W. C. W. Che, "In-vitro and invivo techniques to measure the dielectric constant of biological tissues at microwave frequencies," 2008 International Conference on Microwave and Millimeter Wave Technology, vol. 2, pp. 2-5, 2008.

[28] IEEE Standards Coordinating Committee 34, IEEE Recommended Practice for Determining the Peak Spatial-Average Specific Absorption Rate (SAR) in the Human Head from Wireless Communications Devices: Measurement Techniques, no. February. 2005. 